\title{
Modulation of PI3K-LXR $\alpha$-dependent lipogenesis mediated by oxidative/nitrosative stress contributes to inhibition of HCV replication by quercetin
}

Sandra Pisonero-Vaquero 1,7, María V García-Mediavilla 1,2,7, Francisco Jorquera 2,3 , Pedro L Majano $^{2,4}$, Marta Benet ${ }^{2,5}$, Ramiro Jover ${ }^{2,5,6}$, Javier González-Gallego ${ }^{1,2}$ and Sonia Sánchez-Campos ${ }^{1,2}$

There is experimental evidence that some antioxidant flavonoids show therapeutic potential in the treatment of hepatitis $\mathrm{C}$ through inhibition of hepatitis $\mathrm{C}$ virus $(\mathrm{HCV})$ replication. We examined the effect of treatment with the flavonols quercetin and kaempferol, the flavanone taxifolin and the flavone apigenin on HCV replication efficiency in an in vitro model. While all flavonoids studied were able to reduce viral replication at very low concentrations (ranging from 0.1 to $5 \mu \mathrm{M}$ ), quercetin appeared to be the most effective inhibitor of HCV replication, showing a marked anti-HCV activity in replicon-containing cells when combined with interferon (IFN) $\alpha$. The contribution of oxidative/nitrosative stress and lipogenesis modulation to inhibition of HCV replication by quercetin was also examined. As expected, quercetin decreased HCV-induced reactive oxygen and nitrogen species (ROS/RNS) generation and lipoperoxidation in replicating cells. Quercetin also inhibited liver X receptor (LXR) $\alpha$-induced lipid accumulation in LXR $\alpha$-overexpressing and replicon-containing Huh7 cells. The mechanism underlying the $\operatorname{LXR} \alpha$-dependent lipogenesis modulatory effect of quercetin in HCV-replicating cells seems to involve phosphatidylinositol 3-kinase (PI3K)/AKT pathway inactivation. Thus, inhibition of the PI3K pathway by LY294002 attenuated LXR $\alpha$ upregulation and HCV replication mediated by lipid accumulation, showing an additive effect when combined with quercetin. Inactivation of the PI3K pathway by quercetin may contribute to the repression of LXR $\alpha$-dependent lipogenesis and to the inhibition of viral replication induced by the flavonol. Combined, our data suggest that oxidative/nitrosative stress blockage and subsequent modulation of PI3K-LXR $\alpha$-mediated lipogenesis might contribute to the inhibitory effect of quercetin on HCV replication.

Laboratory Investigation (2014) 94, 262-274; doi:10.1038/labinvest.2013.156; published online 3 February 2014

KEYWORDS: HCV replication; lipogenesis; LXR $\alpha$; oxidative stress; PI3K/AKT pathway; quercetin

Hepatitis C virus (HCV) is a positive-sensed, single-stranded RNA virus of the Flaviviridae family. ${ }^{1}$ The genome of the human HCV encodes a polyprotein post-translationally cleaved by both viral and cellular proteases to produce four structural (core, E1, E2 and p7) and six non-structural (NS2, NS3, NS4A, NS4B, NS5A and NS5B) proteins. ${ }^{2} \mathrm{HCV}$ is a major cause of viral hepatitis, with estimated 150-200 million people infected worldwide. Approximately $70 \%$ of patients suffer from persistent infection, which causes chronic hepatitis and induces several complex mechanisms leading to inflammation, insulin resistance, steatosis, fibrosis and hepatocellular carcinoma. ${ }^{3}$

Although the molecular mechanisms of $\mathrm{HCV}$ pathogenesis remain unclear, oxidative/nitrosative stress associated with reactive oxygen and nitrogen species (ROS/RNS) generation is emerging as a key step and a major initiator in the development and the progression of liver damage. ${ }^{4-7}$

Hepatic steatosis is often observed in patients with chronic hepatitis $\mathrm{C}$ and has been reported to be associated with insulin resistance and progression of fibrosis in the liver. ${ }^{8,9}$

\footnotetext{
${ }^{1}$ Institute of Biomedicine (IBIOMED), University of León, León, Spain; ${ }^{2}$ Centro de Investigación Biomédica en Red de Enfermedades Hepáticas y Digestivas (CIBERehd), Instituto de Salud Carlos III, Madrid, Spain; ${ }^{3}$ Department of Gastroenterology, Complejo Asistencial Universitario de León, León, Spain; ${ }^{4}$ Molecular Biology Unit, Hospital Universitario de la Princesa, Instituto de Investigación Sanitaria Princesa (IP), Madrid, Spain; ${ }^{5}$ Experimental Hepatology Unit, IIS Hospital La Fe, Valencia, Spain and ${ }^{6}$ Department of Biochemistry and Molecular Biology, University of Valencia, Valencia, Spain

Correspondence: Dr S Sánchez-Campos, PhD, Institute of Biomedicine, University of León, Campus de Vegazana, 24071, León, Spain.

E-mail: ssanc@unileon.es

${ }^{7}$ These authors contributed equally to this work.

Received 26 July 2013; revised 28 November 2013; accepted 23 December 2013
} 
The molecular mechanisms of HCV-associated steatosis are poorly understood, ${ }^{10}$ but they are mediated in large part by changes in lipogenic and oxidative stress-mediated proinflammatory cytokines gene expression associated with HCV proteins. ${ }^{3,7,11}$ Thus, NS5A and core proteins colocalize on lipid droplets and activate various pathways of lipid metabolism, contributing to the development of HCV-associated steatosis. ${ }^{12,13}$ Moreover, lipid accumulation is necessary for successful HCV replication. ${ }^{14}$ In this respect, we recently showed that HCV replication induces liver $\mathrm{X}$ receptor (LXR) $\alpha$-mediated intracellular lipid accumulation, which in turn contributes to the efficient replication of HCV. ${ }^{15}$

As oxidative stress has a central role in hepatitis $\mathrm{C}$ pathogenesis and progression, antioxidants have been proposed as therapeutic agents and drug coadjuvants. Much attention has been given to the potential health-promoting properties of flavonoids due to their reported wide range of activities in the prevention of common diseases, including coronary heart disease, cancer, neurodegenerative disease, gastrointestinal disorders and others. ${ }^{16-18}$ Information on the potential benefits of flavonoids in the treatment of hepatitis $\mathrm{C}$ is relatively limited and sometimes contradictory, ${ }^{19,20}$ although some flavonoids, including quercetin, one of the most abundant flavonol-type flavonoids present in the human diet, seem to inhibit the replication of $\mathrm{HCV}^{21-23}$

On the basis of these data, in the current research we explored the effects of different natural antioxidant flavonoids on HCV replication in an in vitro model. We have previously described that important differences exist between flavonoids with different structural features in their capacity to abrogate the generation of different ROS/RNS. ${ }^{24}$ Therefore, we examined the effect of the flavonols quercetin and kaempferol, the flavanone taxifolin and the flavone apigenin on HCV replication efficiency. Because results obtained indicated that quercetin was the most effective inhibitor of HCV replication, we aimed to investigate the molecular mechanisms involved in the modulation of HCV replication by this flavonol, focusing on its effects on ROS and RNS generation and lipid peroxidation, lipid accumulation and $\operatorname{LXR} \alpha$ gene expression. In view of our previous findings showing that phosphatidylinositol 3-kinase (PI3K) pathway inhibition attenuates $\mathrm{LXR} \alpha$ upregulation induced by $\mathrm{HCV}$ expression, ${ }^{15}$ we also examined the role of the PI3K/AKT pathway in lipogenesis modulation by quercetin in our in vitro model.

\section{MATERIALS AND METHODS}

\section{Cells, Cell Culture and Treatment Protocols}

Huh7 cells expressing full-length genotype $1 \mathrm{~b}$ HCV replicons (HCV-G1) were established as previously described. ${ }^{25} \mathrm{HCV}$ G1 cells were treated with human interferon (IFN) $\alpha-2 b$ (PBL Interferon Source, Piscataway, NJ, USA) to eliminate replicons, and were used as control cured cells (Huh7). Huh7 and their derivatives were grown at $37^{\circ} \mathrm{C}$ with a $5 \% \mathrm{CO}_{2}$ atmosphere in Dulbecco's modified Eagle's medium, supplemented with $10 \%$ fetal calf serum, $2 \mathrm{mM}$ L-glutamine and $50 \mathrm{mg} / \mathrm{ml}$ gentamycin. HCV-G1 cells were selected by growth in culture medium containing G418. To prevent phenotypic drift, the cultures were used for only $8-10$ weeks before reverting to frozen stocks from an early passage.

HCV-G1 cells were treated with the flavonols quercetin and kaempferol, the flavanone taxifolin and the flavone apigenin (Sigma-Aldrich, Madrid, Spain) (Figure 1a) in concentrations ranging from 0.1 to $5 \mu \mathrm{M}$ for $48 \mathrm{~h}$ to evaluate their potential to inhibit HCV replication. Then, to analyze the molecular mechanisms involved in HCV inhibition by quercetin, we treated HCV-G1 cells with $0.1-0.5-1-5 \mu \mathrm{M}$ quercetin with or without $0.5 \mathrm{U} / \mathrm{ml} \mathrm{IFN} \alpha-2 \mathrm{~b}$ for $48 \mathrm{~h}$. HCVreplicating cells were also treated with $50 \mathrm{U} / \mathrm{ml}$ IFN $\alpha-2 \mathrm{~b}$ as a control of replication inhibition. Finally, we investigated the effect of PI3K chemical inhibition by treating repliconcontaining cells with LY294002 (Tocris Bioscience, Bristol, UK). ${ }^{26}$ Thus, HCV-G1 cells were pretreated for $8 \mathrm{~h}$ with $50 \mu \mathrm{M}$ LY294002 and then with or without quercetin (0.1$5 \mu \mathrm{M})$ or IFN $\alpha-2 \mathrm{~b}(0.5$ and $50 \mathrm{U} / \mathrm{ml})$ for an additional $48 \mathrm{~h}$. The vehicle used for all treatments was DMSO (0.05\%). HCV-G1 control cells were incubated with DMSO alone (vehicle-treated cells).

\section{Cell Viability in Cell Culture}

The cell viability was assessed by the mitochondrial function, measured by 3-(4,5-dimethylthiazol-2-yl)-2,5-diphenyltetrazolium bromide (MTT) reduction activity for measuring cell proliferation and cytotoxicity as previously reported. ${ }^{27}$ Briefly, cells were seeded in a 24-well plate and incubated with the different treatments. After treatment, the cells were incubated with $0.5 \mathrm{mg} / \mathrm{ml}$ MTT (Sigma-Aldrich) for $2 \mathrm{~h}$ at $37^{\circ} \mathrm{C}$. Subsequently, the media were aspirated and the cells were lysed with DMSO, where after the absorbance was read at $560 \mathrm{~nm}$, with background subtraction at $650 \mathrm{~nm}$, using a microplate reader (Bio-Rad Laboratories, Veenendaal, The Netherlands).

\section{Flow Cytometry and Fluorescence Microscopy}

ROS and RNS production, lipid peroxidation and lipid accumulation were assessed by flow cytometry. The ROS and RNS production was analyzed by flow cytometry as the fluorescence of $2^{\prime}, 7^{\prime}$-dichlorofluorescein (DCF) and ethidium $(\mathrm{ETH})$, which are the oxidation products of $2^{\prime}, 7^{\prime}$ dichlorodihydrofluorescein diacetate (DCFH-DA; SigmaAldrich) and dihydroethidium (DHE; Molecular Probes, Leiden, The Netherlands) with a sensitivity for $\mathrm{H}_{2} \mathrm{O}_{2}$ /NO-based radicals and $\mathrm{O}_{2}{ }^{\bullet-}$, respectively. ${ }^{24}$ The lipid content and lipid peroxidation in cultured cells were determined using Bodipy 493/503 and Bodipy 581/591 $C_{11}$, respectively (Invitrogen, Carlsbad, CA, USA). Briefly, cell monolayers were washed twice with $\mathrm{PBS}$ and incubated with the corresponding dye solution $(5 \mu \mathrm{M}$ for DCFH-DA and DHE or $1 \mu \mathrm{g} / \mathrm{ml}$ for Bodipy $493 / 503$ and $581 / 591 \quad \mathrm{C}_{11}$ ) for $15-45 \mathrm{~min}$ at $37^{\circ} \mathrm{C}$, then washed twice, resuspended in PBS, and analyzed on a FACSCalibur flow cytometer (Becton Dickinson 
a<smiles>O=c1c(O)c(-c2ccc(O)c(O)c2)oc2cc(O)cc(O)c12</smiles><smiles>O=c1c(O)c(-c2ccc(O)cc2)oc2cc(O)cc(O)c12</smiles><smiles>O=C1c2cc(O)cc(O)c2O[C@H](O)[C@H]1c1ccc(O)c(O)c1</smiles><smiles>O=c1cc(-c2ccc(O)cc2)oc2cc(O)cc(O)c12</smiles>

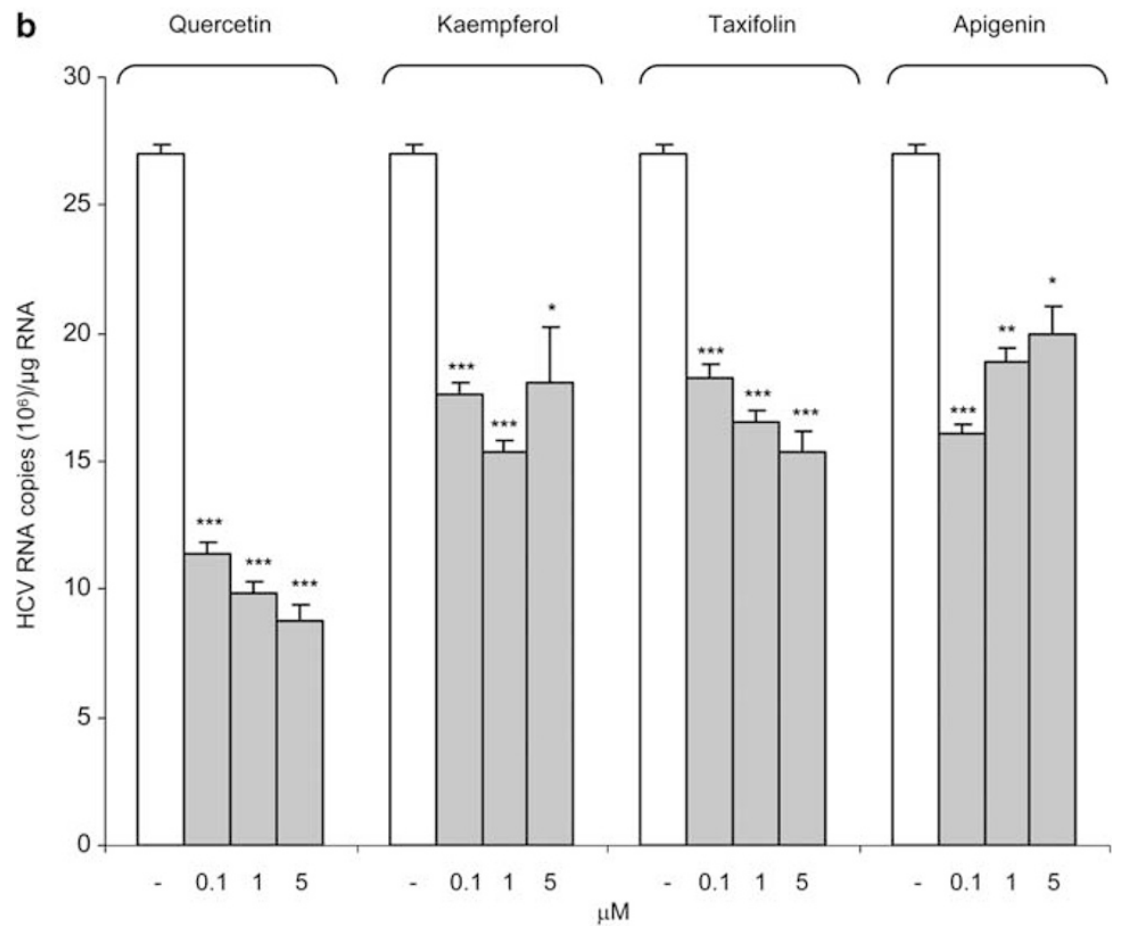

Figure 1 (a) Chemical structure of the flavonols quercetin and kaempferol, the flavanone taxifolin and the flavone apigenin. (b) Effect of the different flavonoids on HCV RNA replication in genomic replicon-containing cells. HCV-G1 cells were incubated with $0.1-5 \mu \mathrm{M}$ quercetin, kaempferol, taxifolin or apigenin. Samples of $1 \mu \mathrm{g}$ RNA were analyzed by real-time RT-qPCR using specific primers to determine HCV RNA levels. Histone H3 mRNA levels were used for sample normalization. Data are expressed as HCV copies/ $\mu$ g total RNA. Data are described as the mean values \pm s.d. of six independent experiments $\left({ }^{*} P<0.05 ;{ }^{* *} P<0.01 ;{ }^{* * *} P<0.001\right.$ vs HCV-G1 vehicle-treated cells).

Biosciences, San Jose, CA, USA). Fluorescence of 10,000 cells was analyzed using the Cell Quest software (Becton Dickinson Biosciences). Indeed, intracellular lipid accumulation was corroborated by fluorescence microscopy using a Nikon Eclipse Ti inverted microscope (Nikon, Amstelveen, The Netherlands). ${ }^{15}$

\section{Triglyceride and Free Fatty Acid Assay}

Intracellular triglyceride (TG) and free fatty acids (FFAs) accumulation were evaluated after the lysis of cells. We collected the supernatants of each group to determine the TG and FFA content in the cell lysates. TG and FFA levels were determined with kits from Biovision Research Products 
(Mountain View, CA, USA) following the guide provided by the company.

\section{Quantitative Real-Time PCR}

Total RNA was obtained by using a Trizol reagent (Life Technologies, Carlsbad, CA, USA). First-strand cDNA was synthesized using the High-Capacity cDNA Archive Kit (Applied Biosystems, Weiterstadt, Germany). For gene expression assays, cDNA was amplified using multiplex realtime PCRs on a StepOne Plus (Applied Biosystems). ${ }^{28}$ TaqMan primers and probes were derived from the commercially available TaqMans ${ }^{\circledR}$ Gene Expression Assays (Applied Biosystems) (Table 1). Relative changes in gene expression levels were determined using the $2^{-\Delta \Delta \mathrm{Ct}}$ method. The cycle number at which the transcripts were detectable (CT) was normalized to the cycle number of GAPDH detection, referred to as $\triangle \mathrm{CT}$. PCR efficiency was determined by TaqMan analysis on a standard curve for targets and endogenous control amplifications that were highly similar. Replication studies were carried out using a SYBR Green kit (Roche Diagnostics $\mathrm{GmbH})$ and two specific primer sets (5'-CCTGTGAGGAA CTACTGTCT- $3^{\prime}$ and $5^{\prime}$-CTATCAGGCAGTACCACAAG- $3^{\prime}$ for $\mathrm{HCV}$, spanning 255 nucleotides of the $5^{\prime}$ non-translated region; 5'-AAAGCCGCTCGCAAGAGTGCG-3' ${ }^{\prime}$ and $5^{\prime}$-ACTT GCCTCCTGCAAAGCAC- $3^{\prime}$ for histone H3). ${ }^{6}$ The number of HCV RNA copies was determined by crossing point interpolation into standard curves, which were generated by reverse transcription of serially diluted, in vitro synthesized viral RNA (genomic) followed by quantitative PCR. The total amount of RNA per reaction was kept constant $(1 \mu \mathrm{g})$ by the addition of Huh7 RNA.

\section{Western Blotting}

Protein extraction and western blotting were performed as described, ${ }^{15}$ using rabbit polyclonal antibodies against $\mathrm{LXR} \alpha$ (Abcam, Cambridge, UK), phospho-AKT (Ser 473) (Santa Cruz Biotechnology, Inc., Santa Cruz, CA, USA), AKT (Santa Cruz Biotechnology), mouse monoclonal antibody against HCV NS5A protein (ViroStat, Portland, ME, USA) and HCV core protein (Thermo Scientific Pierce, Rockford, IL, USA). Bound primary antibody was detected with HRP (horseradish peroxidase)-conjugated anti-rabbit or anti-mouse antibodies (DAKO, Glostrup, Denmark), and blots were developed using

Table 1 Primers and probes used for the RT-qPCR

\begin{tabular}{lcccc}
\hline Gene & GenBank & Assay ID & Amplicon size & Dye \\
\hline LXR $\alpha$ & NM_005693.2 & Hs00172885_m1 & 78 & FAM $^{\text {TM }}$ \\
FAS & NM_004104 & Hs01005611_m1 & 103 & FAM $^{\text {TM }}$ \\
GAPDH & NM_002046.3 & 4326317E & 122 & VIC $^{\text {TM }}$
\end{tabular}

Abbreviations: $\mathrm{LXR} \alpha$, liver $\mathrm{X}$ receptor alpha; FAS, fatty acid synthase; GAPDH, glyceraldehyde-3-phosphate dehydrogenase. an enhanced chemiluminescence detection system (ECL kit; Amersham Pharmacia, Uppsala, Sweden). The density of the specific bands was quantified with an imaging densitometer (Scion Image, Frederick, MD, USA).

\section{Adenoviral Vectors}

The recombinant adenovirus encoding $\operatorname{LXR} \alpha$ was constructed as follows: human $\mathrm{LXR} \alpha \mathrm{cDNA}$ was kindly provided by Dr D Mangelsdorf (UT Southwestern Medical Center, Dallas, Texas). The coding sequence was released from the plasmid pCMX with KpnI-BamHI, and subcloned in the adenoviral shuttle vector $\mathrm{pAC} / \mathrm{CMVpLpA}{ }^{29}$ pre-digested with the same restriction enzymes. The resulting shuttle plasmid and the pJM17 were co-transfected into 293 cells to allow homologous recombination and generate the $\operatorname{Ad}-\operatorname{LXR} \alpha$ adenovirus. Cell monolayers of human hepatoma Huh7 cell line were infected with recombinant adenovirus encoding transcription factor or with an insertless adenoviral vector (Ad-CONT) for $24 \mathrm{~h}$ at a multiplicity of infection (MOI) of 15-30 plaque-forming units/cell. LXR $\alpha$ ligand T0901317 (Sigma-Aldrich) $(10 \mu \mathrm{M})$ was added at $24 \mathrm{~h}$ post infection and at $48 \mathrm{~h}$ post infection cells were treated with $0.1-5 \mu \mathrm{M}$ of quercetin or IFN $\alpha-2 b(0.5$ and $50 \mathrm{U} / \mathrm{ml})$. Finally, cells were harvested and analyzed.

\section{Immunofluorescence Analysis}

Immunofluorescence analysis was performed as previously described. ${ }^{15}$ Coverslips were incubated with rabbit anti-LXR $\alpha$ antibody (Abcam) at $4{ }^{\circ} \mathrm{C}$ overnight. Thereafter, the secondary antibody donkey anti-rabbit conjugated with FITC (Jackson ImmunoResearch, Baltimore, PA, USA) was applied. Nuclei were stained with DAPI (blue). After washing, the coverslips were mounted on DakoCytomation Fluorescent Mounting Medium (DAKO). The preparations were analyzed with an inverted fluorescence microscope (Nikon Eclipse Ti-U).

\section{Statistical Analysis}

Results are expressed as the mean \pm standard deviation. Significant differences were evaluated by one way analysis of variance (ANOVA) and Newman-Keul's test. $P<0.05$ was considered to be significant for a difference.

\section{RESULTS \\ Quercetin is the Most Effective Inhibitor of HCV Replication}

To examine the effect of treatment with different flavonoids on HCV replication efficiency, HCV-G1 cells were cultured with quercetin, kaempferol, taxifolin and apigenin in concentrations ranging from 0.1 to $5 \mu \mathrm{M}$ or vehicle. At these very low concentrations, flavonoids exhibit no cellular toxicity and the limited antiperoxidative capacity does not interfere with their anti-HCV activity. ${ }^{30}$ As shown in Figure 1b, all flavonoids were able to significantly reduce the HCV RNA copy number (K0.1: $-35 \%, \mathrm{~K} 1:-43 \%$; T0.1: $-32 \%$, T1: $-39 \%$; T5: $-43 \%$; A0.1: $-40 \%$, A1: $-30 \%$, vs 
non-treated cells), but quercetin appeared to be the most effective inhibitor of HCV replication at doses resembling human plasma concentrations upon quercetin supplementation. ${ }^{31}$

In view of these findings, HCV-G1 cells were incubated with quercetin at concentrations of $0.1,0.5,1$ and $5 \mu \mathrm{M}$ alone or combined with IFN $\alpha 0.5$ (Figure 2). HCV-G1 cells were also treated with IFN $\alpha 50$ as a control of replication inhibition $(-90 \%$, vs non-treated cells). As expected, quercetin significantly decreased HCV replication at all tested concentrations in a dose-dependent manner (Q0.1: - 49\%, Q0.5: - 52\%, Q1: - 57\%, Q5: - 61\%; Figure 2a) compared with untreated cells. When combined with IFN $\alpha 0.5$, a higher antiviral effect was observed (Q0.1: $-55 \%$, Q0.5: $-62 \%$, Q1: $-68 \%$, Q5: $-72 \%$, vs HCV-G1 vehicle-treated cells), surpassing the HCV inhibitory effect of IFN $\alpha 0.5$ alone (Q0.5: - 24\%, Q1: - 34\%, Q5: - 43\%, vs HCV-G1 IFN 0.5 cells) (Figure 2a). As shown in Supplementary Figure 1, this antiviral activity is not associated with cytotoxicity and cell proliferation impairment. Similarly, quercetin was able to dose dependently reduce HCV NS5A and core proteins in replicon-containing cells (NS5A, Q0.1: $-24 \%$, Q0.5: $-27 \%$, Q1: - 54\%, Q5: - 67\%; core, Q0.5: - 32\%, Q1: $-50 \%$, Q5: $-62 \%$; Figure 2b) compared with untreated cells, showing a marked inhibitory effect when combined with IFN $\alpha$ 0.5 (NS5A, Q0.1: - 62\%, Q0.5: - 67\%, Q1: - 71\%, Q5: - 78\%; core, Q0.1: $-51 \%$, Q0.5: $-53 \%$, Q1: $-63 \%$,
Q5: - 70\%, vs HCV-G1 vehicle-treated cells). Moreover, combined treatment inhibited HCV replication more than IFN alone (NS5A, Q0.5: - 21\%, Q1: - 32\%, Q5: - 48\%; core, Q0.1: $-16 \%$, Q0.5: - 19\%, Q1: - 37\%, Q5: $-49 \%$, vs HCV-G1 IFN 0.5 cells) (Figure $2 \mathrm{~b}$ ).

\section{Quercetin Inhibits Oxidative and Nitrosative Stress in HCV-G1 Cells}

To address the contribution of the antioxidant capacity of quercetin to the inhibition of HCV replication, we investigated the generation of ROS/RNS and lipid peroxidation in replicon-containing cells by flow cytometry. HCV-G1 cells were incubated with quercetin $(0.1-5 \mu \mathrm{M})$ or just DMSO for $48 \mathrm{~h}$. As shown in Figure 3, viral replication induced oxidative and nitrosative stress, as indicated by the significantly increased generation of different ROS/RNS (DCF: $+55 \%$, ETH: $+56 \%)$ and lipoperoxidation $(+350 \%)$ compared with Huh7 cells. Analysis of histograms in which the fluorescence was plotted against the relative cells number (Figure $3 \mathrm{a}$ and $\mathrm{b}$, top) and quantification of the corresponding fluorescence intensity (Figures $3 a-c$ ) indicated that quercetin significantly abrogated the HCV-induced ROS/RNS overproduction (DCF: Q0.5: - 13\%, Q1: - 22\%, Q5: - 28\%; ETH: Q0.1: $-29 \%$, Q0.5: - 32\%, Q1: - 34\%, Q5: - 35\%, vs HCV-G1 vehicle-treated cells) and partially reduced the oxidation of lipids increased in HCV-G1 cells (Q0.5: $-25 \%$, Q1: $-27 \%$, Q5: - 30\%). Similarly, IFN $\alpha 50$ significantly

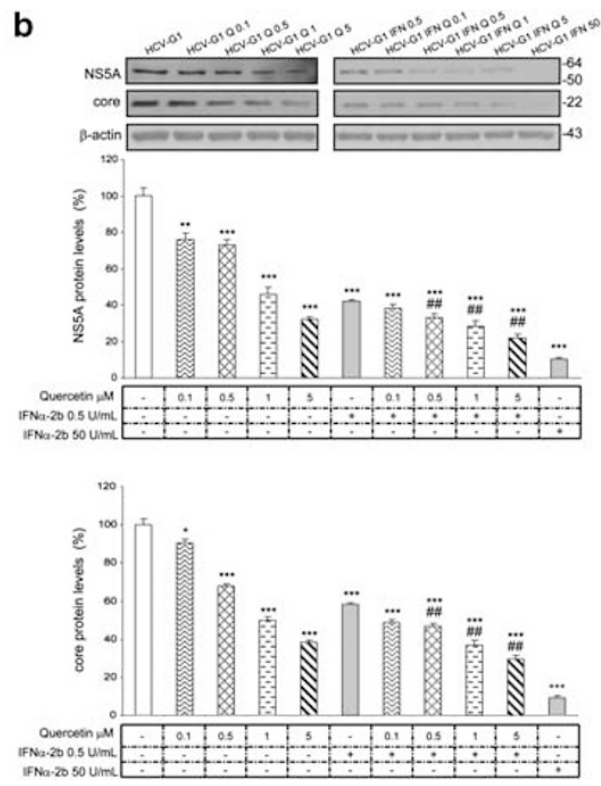

Figure 2 Effect of quercetin treatment and its combination with IFN $\alpha$ on viral replication and HCV NS5A and core protein levels. HCV-G1 cells were incubated with quercetin alone or in combination with IFN $\alpha-2 \mathrm{~b}(0.5 \mathrm{U} / \mathrm{ml})$ at indicated concentrations for $48 \mathrm{~h}$. (a) Samples of $1 \mu \mathrm{g}$ RNA were analyzed by real-time RT-qPCR using specific primers to determine HCV RNA levels. Histone H3 mRNA levels were used for sample normalization. HCV-G1 cells were treated with $50 \mathrm{U} / \mathrm{ml}$ IFN $\alpha-2 \mathrm{~b}$ as a control of replication inhibition. Results are expressed as HCV RNA copies/ $\mu \mathrm{g}$ total RNA. (b) NS5A and core protein levels were analyzed by western blotting. Densitometry analysis of specific bands expressed as the percentage relative to HCV-G1 cells (100\%). $\beta$-Actin levels were used as a loading control. Molecular weight markers $(\mathrm{kDa})$ are indicated on the right. Photographs are representative of eight independent experiments. Data are described as the mean values \pm s.d. of eight independent experiments $\left({ }^{*} P<0.05 ;{ }^{* *} P<0.01 ;{ }^{* * *} P<0.001\right.$ vs $\mathrm{HCV}-\mathrm{G} 1$ vehicle-treated cells, ${ }^{\# \#} P<0.01$ vs HCV-G1 IFN 0.5). 
a
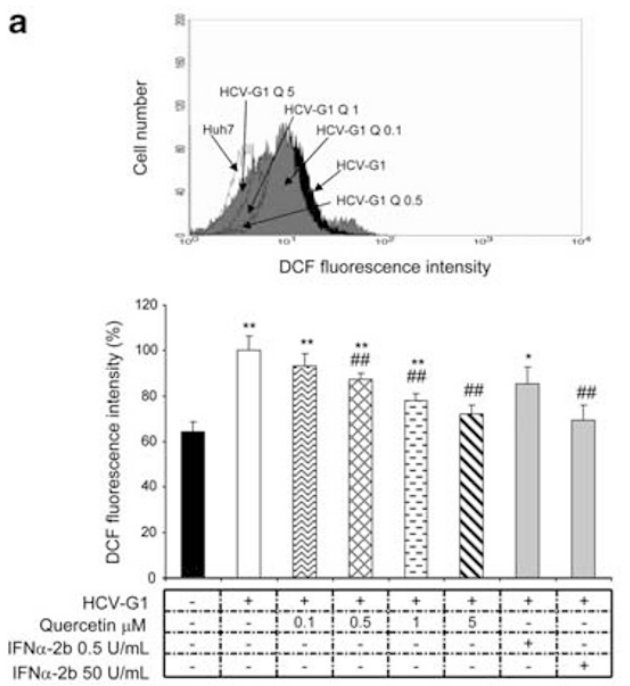

b
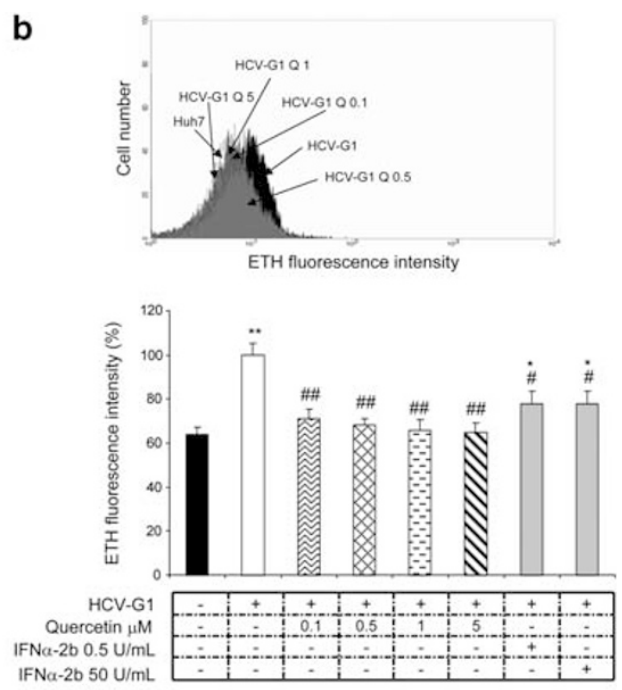

c

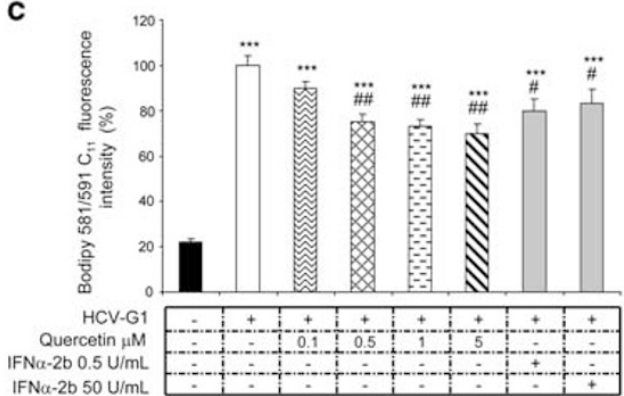

Figure 3 Quercetin inhibits ROS and RNS production and lipid peroxidation induced by viral replication. HCV-G1 cells were incubated with quercetin at indicated concentrations for $48 \mathrm{~h}$, and then ROS and RNS and lipid peroxidation were determined by flow cytometry as described. (a) Representative histograms of DCF fluorescence. The fluorescence is plotted against the number of cells. Results are expressed as DCF relative fluorescence intensity and normalized to HCV-G1 cells (100\%). (b) Representative histograms of ETH fluorescence. The fluorescence is plotted against the number of cells. Results are expressed as ETH relative fluorescence intensity and normalized to HCV-G1 cells (100\%). (c) Lipid peroxidation expressed as Bodipy $581 / 591$ $C_{11}$ fluorescence intensity as the percentage relative to HCV-G1 cells (100\%). Data are described as the mean values \pm s.d. of six separate experiments $\left({ }^{*} P<0.05 ;{ }^{* *} P<0.01 ;{ }^{* * *} P<0.001\right.$ vs Huh7, ${ }^{\#} P<0.05 ;{ }^{\# \#} P<0.01$ vs HCV-G1 vehicle-treated cells).

decreased ROS/RNS generation (DCF: - 30\%; ETH: - 22\%) and lipid peroxidation $(-17 \%)$ in HCV-replicating cells (Figures $3 \mathrm{a}-\mathrm{c}$ ). These results suggest that the modulation of oxidative and nitrosative stress by quercetin may also have an important role in its anti-HCV activity.

\section{Quercetin Decreases HCV-Induced Intracytoplasmatic Lipid Accumulation}

To establish the contribution of lipid metabolism modulation to the inhibition of HCV replication by quercetin, we examined the effect of this flavonol on intracytoplasmatic lipid accumulation in HCV-G1 cells. Results of flow-cytometric analysis of Bodipy 493/503-stained HCV-G1 cells are presented in Figure 4a. As shown, lipid accumulation increased significantly in replicon-containing cells $(+257 \%)$ compared with Huh7 cells. In addition, quercetin treatment significantly decreased HCV-induced intracellular lipid accumulation in a dose-dependent manner (Q0.5: $-17.5 \%, \mathrm{Q} 1$ : $-22 \%$, Q5: $-55 \%$, vs HCV-G1 vehicle-treated cells).
Representative fluorescence images of Bodipy 493/503stained cells, corroborating the results obtained by flow cytometry, are exhibited in Figure 4c. We next analyzed the intracellular TG and FFA accumulation and, as expected, TG and FFA contents were significantly enhanced in replicating cells ( +150 and $+81 \%$, respectively) compared with Huh7 cells (Figure 4b). Further, HCV-induced TG and FFA concentrations were significantly reduced by quercetin (TG: Q0.5: $-31 \%$, Q1: - 40\%, Q5: - 49\%; FFA: Q0.5: - 23\%, Q1: $-24 \%$, Q5: $-26 \%$, vs HCV-G1 vehicle-treated cells). Finally, IFN $\alpha 50$ was also able to decrease intracellular HCV-mediated lipid accumulation $(-20 \%)$ by reducing TG content and FFA concentration $(-44$ and $-36 \%$, respectively) (Figures $4 \mathrm{a}-\mathrm{c}$ ).

\section{Quercetin Downregulates Lipogenic Gene Overexpression Associated with HCV Replication}

There is experimental evidence that $\operatorname{LXR} \alpha$ induces the expression of lipogenic genes involved in fatty acid synthesis. ${ }^{32}$ 
a
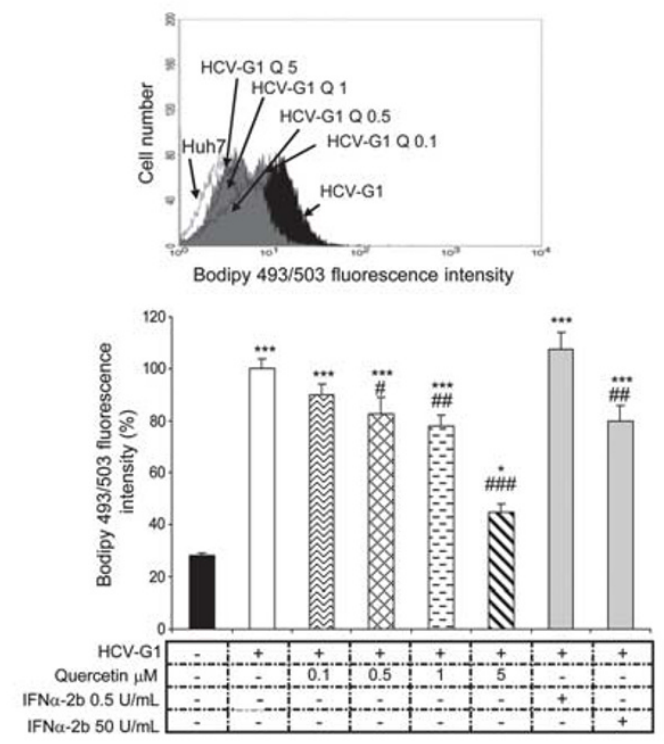

b
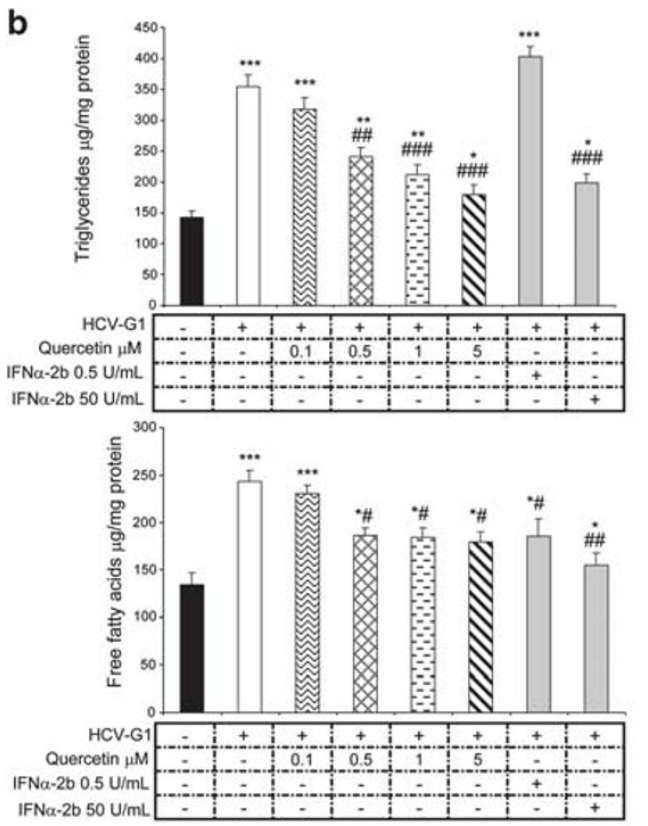

c
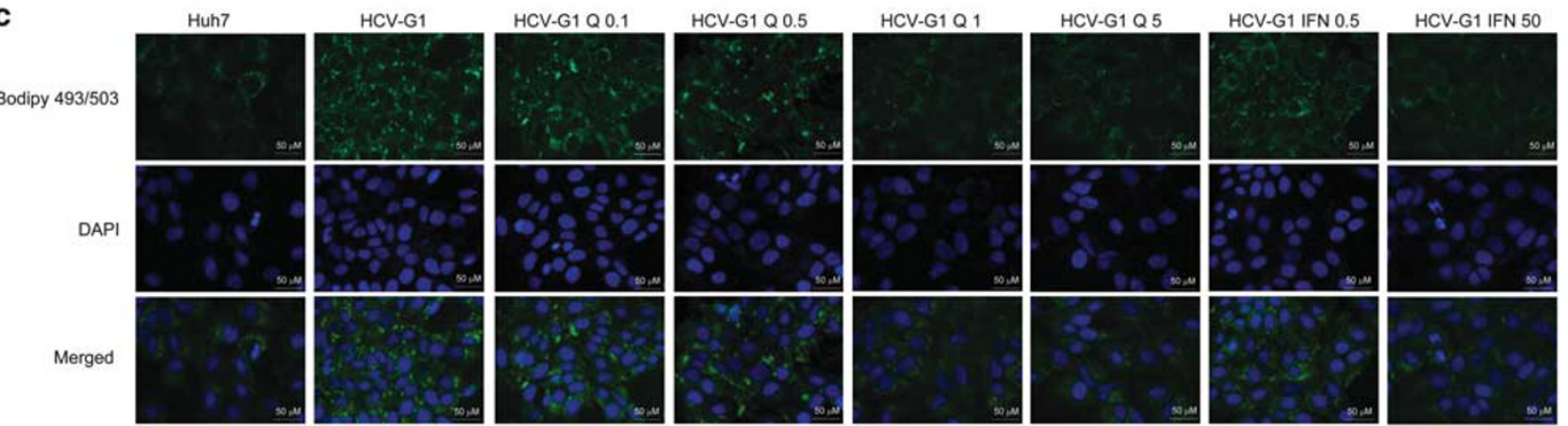

Figure 4 HCV-induced intracytoplasmatic lipid accumulation is decreased by quercetin treatment. HCV-G1 cells were incubated with quercetin at indicated concentrations for $48 \mathrm{~h}$, and then intracellular lipid accumulation was determined as described. (a) Representative histograms of Bodipy 493/ 503 fluorescence. Results are expressed as Bodipy relative fluorescence intensity and normalized to HCV-G1 cells (100\%). (b) Triglyceride and free fatty acid assays were performed on cell lysates as indicated in Materials and Methods. Triglyceride and free fatty acid were normalized by protein content. Data are described as the mean values \pm s.d. of six experiments $\left({ }^{*} P<0.05 ;{ }^{* *} P<0.01 ;{ }^{* * *} P<0.001\right.$ vs Huh7, $P<0.05 ;{ }^{\# \#} P<0.01 ;{ }^{\# \# \#} P<0.001$ vs HCV-G1 vehicle-treated cells). (c) Representative fluorescent images of Bodipy 493/503-treated cells (green). Nuclei were stained with DAPI (blue). The merged image with green and blue fluorescence is also shown. Photographs shown are typical results of six independent experiments.

Thus, we investigated the role of the LXR $\alpha$-dependent pathway in quercetin-mediated inhibition of intracytoplasmatic lipid accumulation. As shown in Figure 5, we observed a significant induction of $L X R \alpha$ gene expression in repliconcontaining cells (mRNA, $+82 \%$, protein, $+55 \%$ ) compared with Huh7 cells. Regarding gene expression of LXR $\alpha$-related lipogenic genes, as expected, we also found a significant increase in fatty acid synthase (FAS) mRNA levels in HCVreplicating cells $(+94 \%$, vs Huh7) (Figure 5b). Interestingly, quercetin was able to significantly decrease $\mathrm{HCV}$-induced $\mathrm{LXR} \alpha$ gene expression at all experimental concentrations (mRNA, Q0.1: $-32 \%$, Q0.5: $-38 \%$, Q1: $-39 \%$, Q5: $-40 \%$; protein, Q0.1: - 16\%, Q0.5: - 19\%, Q1: - 35\%, Q5: $-34 \%$ ) (Figures $5 \mathrm{a}$ and $\mathrm{b}$ ). Similarly, mRNA levels of FAS were significantly decreased by quercetin treatment $(\mathrm{Q} 0.1$ : - 16\%, Q0.5: - 14\%, Q1: - 17\%, Q5: - 20\%) compared with HCV-G1 vehicle-treated cells (Figure 5b). Noteworthy, IFN $\alpha$ also decreased $\operatorname{LXR} \alpha$ induction (IFN $\alpha$ 0.5: mRNA, $-25 \%$, protein, $-31 \%$; IFN $\alpha$ 50: mRNA, $-45 \%$, protein, $-58 \%$; Figures $5 \mathrm{a}$ and $\mathrm{b}$ ) and subsequent FAS overexpression (IFN $\alpha$ 0.5: $-30 \%$; IFN $\alpha$ 50: $-68 \%$ ) in HCV-G1 cells (Figure 5b).

\section{Effect of Quercetin on LXR $\alpha$ Overexpression Induced by Adenoviral Infection}

To corroborate the effect of quercetin on LXR $\alpha$ gene expression, human hepatoma Huh7 cells were infected with adenoviral vector encoding LXR $\alpha$ transcription factor. We first examined 

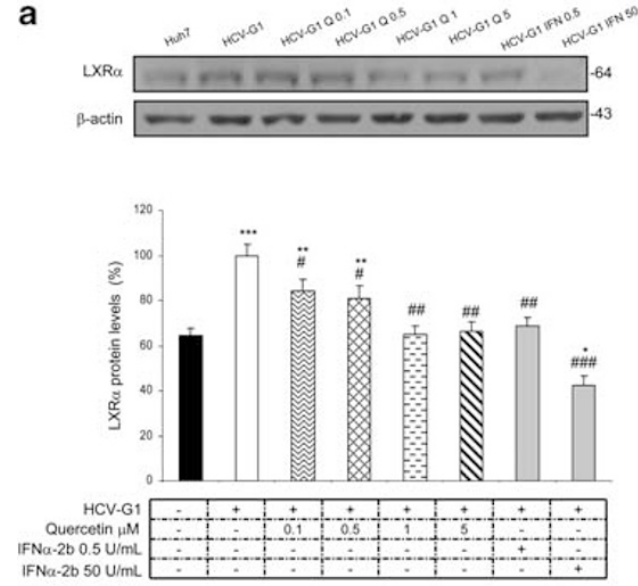

b

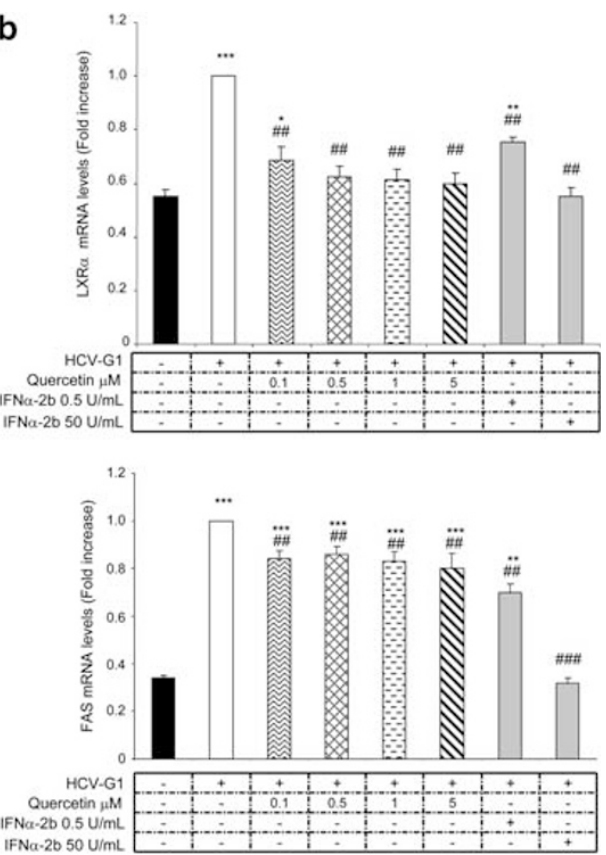

Figure 5 Quercetin inhibits HCV-induced lipogenic gene overexpression. HCV-G1 cells were incubated with quercetin at indicated concentrations for $48 \mathrm{~h}$, and then LXR $\alpha$ and FAS gene expression was determined as indicated. (a) LXR $\alpha$ protein levels were analyzed by western blotting. Densitometry analysis of specific bands expressed as the percentage relative to HCV-G1 cells (100\%). $\beta$-Actin levels were used as a loading control. Molecular weight markers $(\mathrm{kDa})$ are indicated on the right. Photographs are representative of six experiments. (b) Bar graphs show LXR $\alpha$ (upper panel) and FAS (bottom panel) mRNA levels determined by real-time RT-qPCR as indicated. Data are described as the mean values \pm s.d. of six independent experiments $\left({ }^{*} P<0.05 ;{ }^{* *} P<0.01 ;{ }^{* * *} P<0.001\right.$ vs Huh7, ${ }^{\#} P<0.05 ;{ }^{\# \#} P<0.01 ;{ }^{\# \# \#} P<0.001$ vs HCV-G1 vehicle-treated cells).

the effect of adenoviral infection on LXR $\alpha$ gene expression. As exhibited in Supplementary Figure 2, RT-qPCR, immunofluorescence microscopy and western blot assays confirmed the overexpression of the nuclear receptor LXR $\alpha$ in Huh7 cells infected with the adenoviral vector (protein, Huh7 Ad-0.5: + 257\%, vs Huh7 Ad-CONT). We next analyzed the effect of quercetin treatment on LXR $\alpha$ mRNA levels and intracytoplasmatic lipid accumulation in Huh7 Ad-0.5 cells (Figures 6a and b, respectively). We observed that quercetin was able to dose dependently reduce $\operatorname{LXR} \alpha$ overexpression caused by adenoviral infection at all tested concentrations (Q0.1: $-27 \%$, Q0.5: $-39 \%$, Q1: $-46 \%$, Q5: - 58\%, vs Huh7 Ad- 0.5 vehicletreated cells; Figure 6a), while the overexpression of the nuclear receptor $\operatorname{LXR} \alpha$ was not affected by IFN $\alpha$ (Figure 6a). Similarly, quercetin also reduced intracellular lipid accumulation at all concentrations, as depicted in representative fluorescence images of Bodipy 493/503-stained cells (Figure 6b). Together, our results clearly indicate that quercetin exerts an inhibitory effect on $\operatorname{LXR} \alpha$ expression and lipid accumulation in our in vitro model of $\operatorname{LXR} \alpha$ overexpression as well as in HCV-replicating Huh7 cells. In view of these findings, we suggest that $\operatorname{LXR} \alpha$ inhibition by quercetin contributes to the modulation of $\mathrm{HCV}$-induced lipogenesis.

\section{PI3K/AKT Pathway is Involved in the Inhibitory Effect of Quercetin on LXR $\alpha$-Mediated Lipogenesis in HCV-G1 Cells}

To investigate the role of the PI3K/AKT pathway in LXR $\alpha$ dependent lipogenesis modulation by quercetin, we first studied the effect of quercetin on AKT activation. As shown in Figure 7a, HCV replication induced a significant increase in AKT phosphorylation $(+117 \%)$ compared with Huh7 cells. Furthermore, quercetin treatment significantly inhibited AKT activation at all experimental concentrations in a dosedependent manner (Q0.1: - 27\%, Q0.5: - 30\%, Q1: - 35\%, Q5: - 43\%, vs HCV-G1 vehicle-treated cells). However, IFN $\alpha$ 50 slightly induced AKT phosphorylation $(+21 \%)$ compared with HCV-G1 cells (Figure 7a). To corroborate that quercetin inhibits HCV-mediated lipogenesis through the PI3K/AKT pathway, we next studied the effects of the PI3K-inhibitor LY294002 alone or combined with quercetin on LXR $\alpha$ gene expression, lipid accumulation and HCV replication efficiency. First, we confirmed that cell viability was not affected by the different treatments (Supplementary Figure 1). As shown in Figures 7b-e, LY294002 treatment caused a significant reduction in $\mathrm{HCV}$ replication, LXR $\alpha$ mRNA levels and lipid accumulation $(-31,-48$, and $-66 \%$, respectively, vs HCV-G1 vehicle-treated cells). Moreover, the antiviral effect was higher when LY294002 and quercetin were 

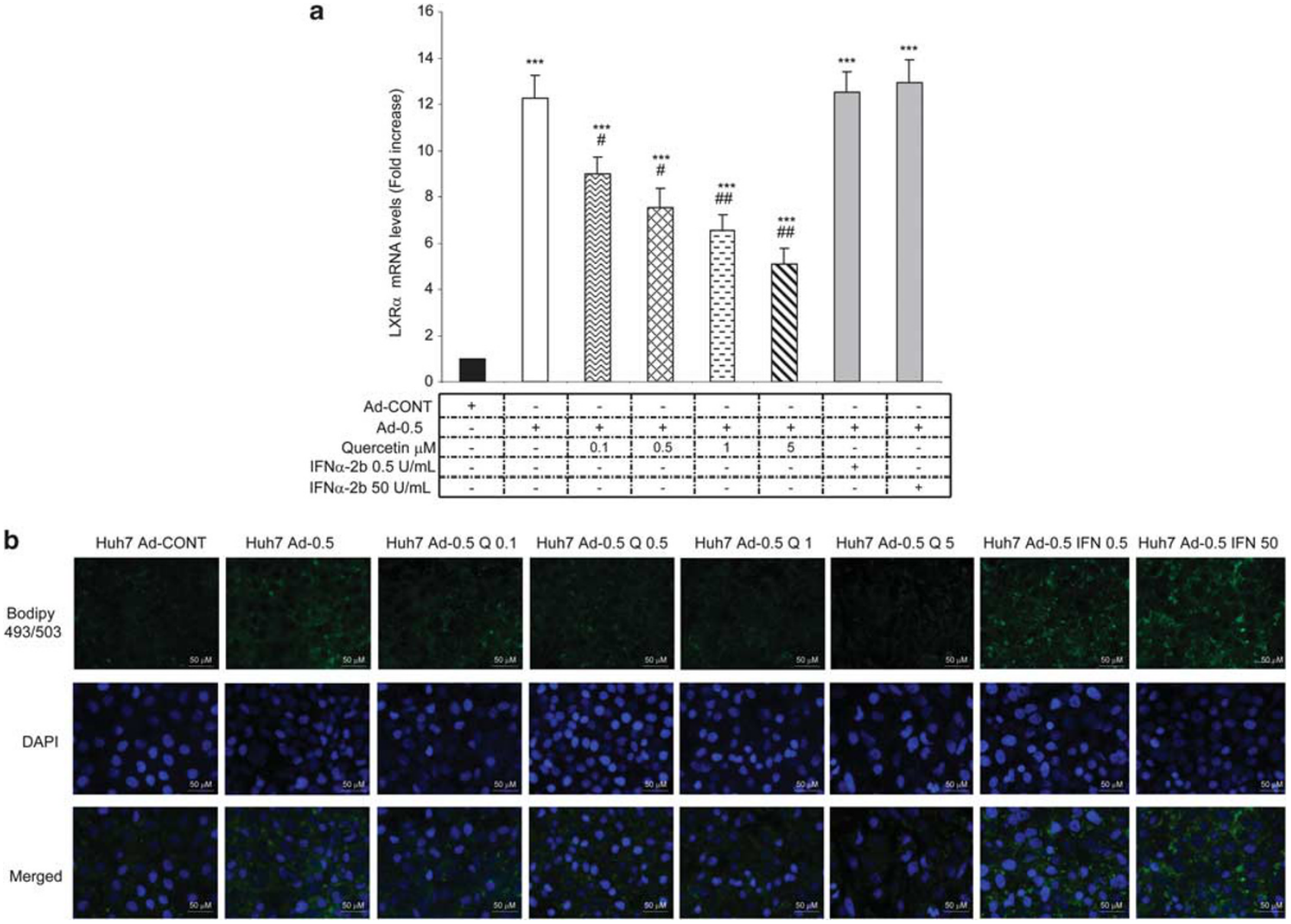

Figure 6 Effect of quercetin treatment on LXR $\alpha$ overexpression induced by adenoviral infection of human hepatoma Huh7 cells. Cells were infected with $0.5 \mu \mathrm{l}$ of the recombinant adenovirus encoding LXR $\alpha$ (Huh7 Ad-0.5) or with an insertless adenoviral vector (Huh7 Ad-CONT). LXR $\alpha$ ligand was added at $24 \mathrm{~h}$ post infection and at $48 \mathrm{~h}$ post infection Huh7 Ad- 0.5 cells were treated with $0.1-5 \mu \mathrm{M}$ of quercetin or IFN $\alpha-2 \mathrm{~b}(0.5 \mathrm{and} 50 \mathrm{U} / \mathrm{ml})$. (a) $\mathrm{LXR} \propto$ mRNA levels were analyzed by RT-qPCR as described. Data are described as the mean values \pm s.d. of eight separate experiments $\left(^{* * *} P<0.001\right.$ vs Huh7 Ad-CONT, ${ }^{\#} P<0.05,{ }^{\# \#} P<0.01$ vs Huh7 Ad-0.5 vehicle-treated cells). (b) Intracellular lipids accumulation was determined by fluorescence microscopy using Bodipy $493 / 503$ as described (green). Nuclei were stained with DAPI (blue). Photographs shown are typical results of six independent experiments.

combined (LY Q0.1: - 53\%, LY Q0.5: - 47\%, LY Q1: - 52\%, LY Q5: - 49\%, vs HCV-G1 vehicle-treated cells; Figure 7b). Furthermore, additive anti-HCV activity was associated with a greater reduction in $\mathrm{LXR} \alpha$ gene expression (LY Q0.1: - 55\%, LY Q0.5: - 59\%, LY Q1: - 66\%, LY Q5: -66\%, vs HCV-G1 vehicle-treated cells; Figure 7c) and lipid accumulation in HCV-G1 cells (LY Q0.1: - 69\%, LY Q0.5: - 67\%, LY Q1: - 82\%, LY Q5: - 84\%; Figures 7d and e). Overall, these results suggest that quercetin-mediated PI3K pathway inactivation may contribute to $\operatorname{LXR} \alpha$-dependent lipogenesis modulation and inhibition of viral replication by the flavonol.

\section{DISCUSSION}

The current Food and Drug administration (FDA)-approved standard of care for chronic HCV is pegylated IFN $\alpha$ combined with ribavirin. However, treatment is ineffective in many HCV patients. $^{33}$ There is experimental evidence that the natural antioxidant flavonoids show therapeutic potential in the treatment of hepatitis $\mathrm{C}$ through inhibition of $\mathrm{HCV}$ replication. ${ }^{21-23}$ The present study suggests for the first time that quercetin might exert an indirect inhibitory effect on HCV replication via oxidative/nitrosative stress blockage and subsequent modulation of $\mathrm{PI} 3 \mathrm{~K}-\mathrm{LXR} \alpha$-mediated lipogenesis associated with steatosis development and hepatitis C progression.

Our preliminary results indicated that all of the flavonoids studied were able to reduce $\mathrm{HCV}$ replication efficiency at very low concentrations. However, quercetin appears to be the most effective modulator of $\mathrm{HCV}$ replication capacity in replicon-containing cells. Furthermore, it has been previously indicated that quercetin also shows antiviral activity and decreases HCV particle production in cell culture, ${ }^{21,22}$ whereby we focused our study on the molecular 
a
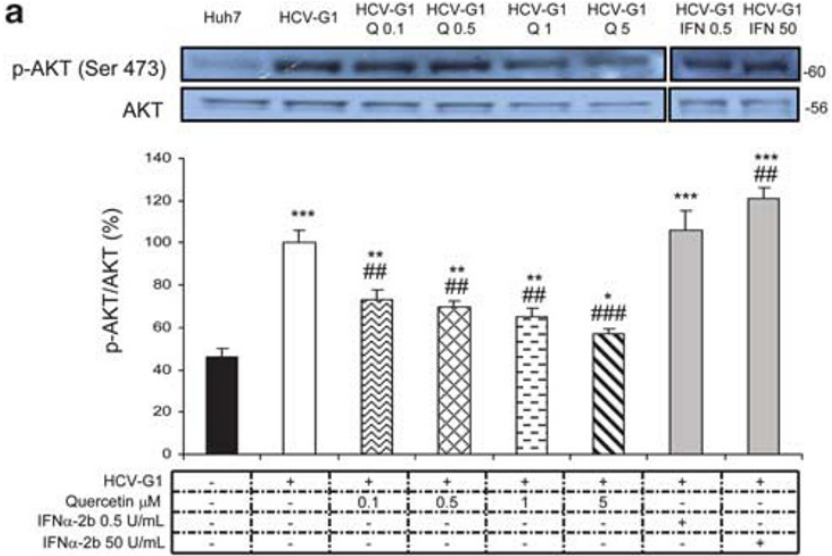

b
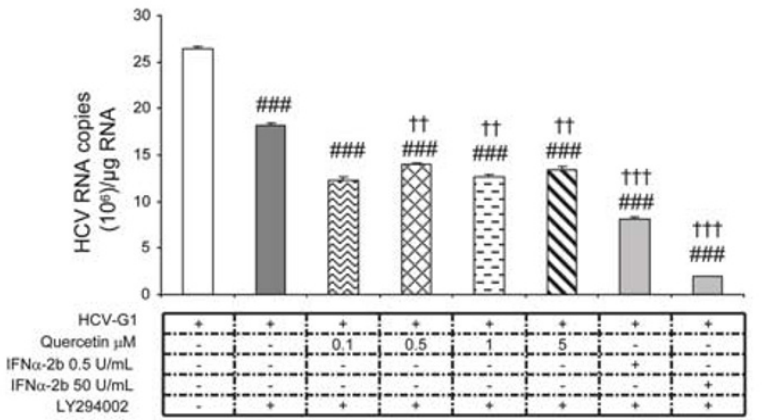

C

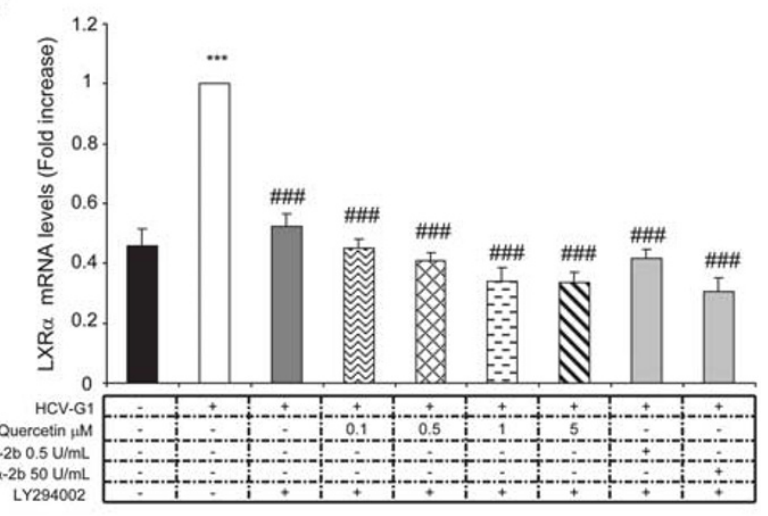

d

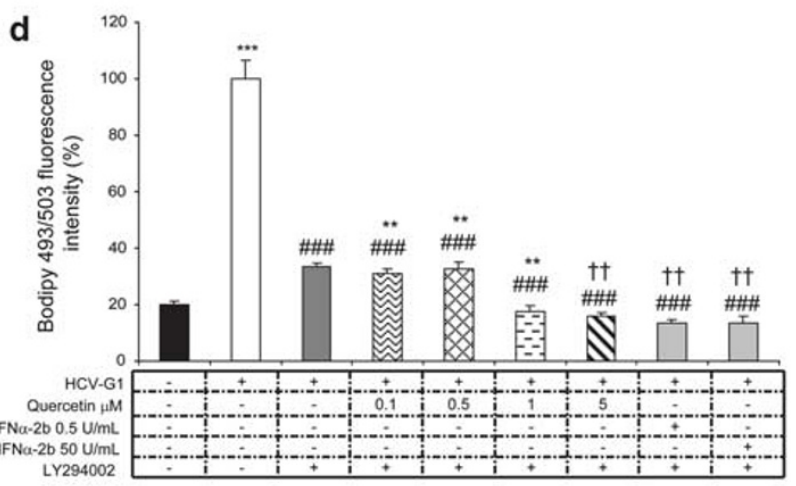

e

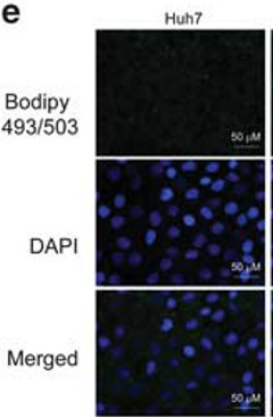

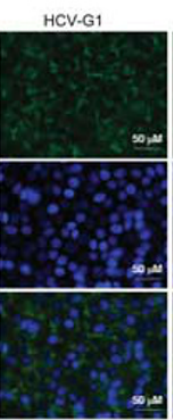
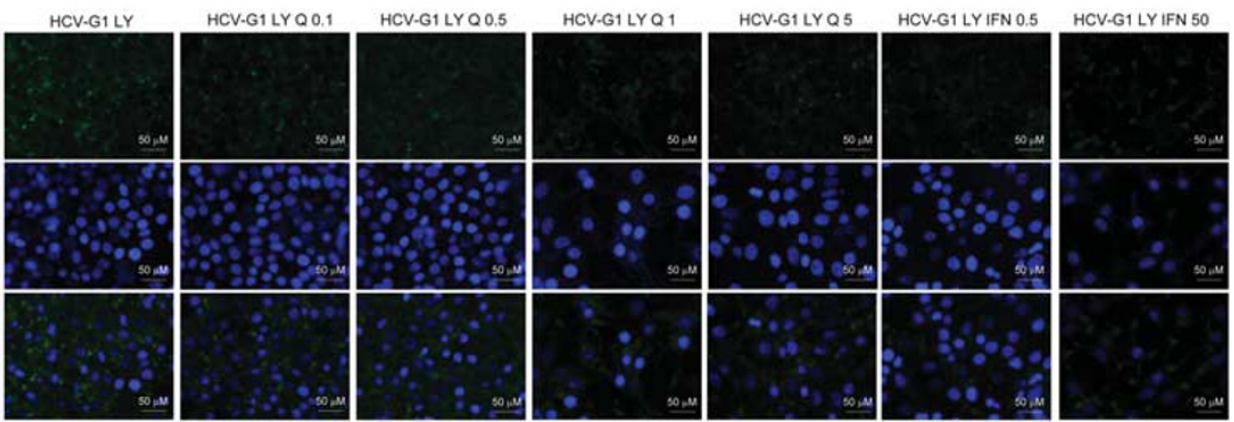

Figure 7 Additive inhibitory effect of quercetin and LY294002 on PI3K/AKT pathway-mediated LXR $\alpha$-dependent lipogenesis induced by viral replication. (a) HCV-G1 cells were incubated with quercetin at indicated concentrations for $48 \mathrm{~h}$, and then p-AKT (Ser 473 ) and AKT protein levels were analyzed by western blotting. Densitometry analysis of specific bands expressed as the percentage relative to HCV-G1 vehicle-treated cells (100\%). $\beta$-Actin levels were used as a loading control. Molecular weight markers $(\mathrm{kDa})$ are indicated on the right. Photographs are representative of six independent experiments. (b-e) HCV-G1 cells were incubated with LY294002 alone or in combination with quercetin or IFN $\alpha$-2b as previously described in Materials and Methods. Then HCV replication, LXR $\alpha$ gene expression and intracytoplasmatic lipid accumulation were determined as described. (b) Samples of $1 \mu \mathrm{g}$ RNA were analyzed by real-time RT-qPCR using specific primers to determine HCV RNA levels. Histone H3 mRNA levels were used for sample normalization. Results are expressed as HCV RNA copies/ $\mu$ g total RNA. (c) Bar graph shows LXR $\alpha$ mRNA levels determined by real-time RT-qPCR as described. (d) Intracellular lipid accumulation expressed as Bodipy 493/503 relative fluorescence intensity and normalized to HCV-G1 cells (100\%).

(e) Representative fluorescent images of Bodipy 493/503-treated cells. Nuclei were stained with DAPI (blue). Photographs shown are typical results of six experiments. Data are described as the mean values \pm s.d. of six independent experiments $\left({ }^{*} P<0.05 ;{ }^{* *} P<0.01 ;{ }^{* * *} P<0.001\right.$ vs Huh7, ${ }^{\# \#} P<0.01$;

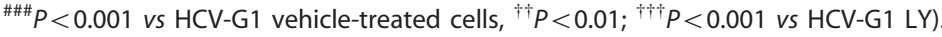

mechanisms involved in HCV replication regulation by this flavonol.

In the present research, a dose-dependent inhibitory effect on HCV replication was obtained with quercetin at all tested concentrations. NS5A protein expression, which is essential for HCV replication, was also reduced by quercetin treatment, as previously described. ${ }^{21}$ Furthermore, the combination of quercetin and IFN $\alpha$ exerted profound inhibitory effects on NS5A protein levels and HCV replication, as shown when curcumin and IFN $\alpha$ were combined. ${ }^{34}$ Similarly, our results 
indicate for the first time an inhibitory effect of quercetin on $\mathrm{HCV}$ core expression, showing an additive effect when combined with IFN $\alpha$. The major pathway for the generation of the antiviral response mediated by IFN $\alpha$ involves a combination of different janus kinase (JAK) and signal transducer and activator of transcription (STAT) proteins to lead the transcription of IFN-stimulated genes. ${ }^{35,36}$ In this regard, it has been described that quercetin may increase the antiviral gene expression regulated by the IFN-activated JAKSTAT pathway. ${ }^{37}$ Nevertheless, the molecular mechanisms involved in quercetin-mediated impairment of HCV replication seem to be more complex. Thereby, quercetin may also inhibit the NS5A-driven augmentation of internal ribosomal entry site (IRES)-mediated translation ${ }^{21,38}$ and reduce viral production by inhibiting both NS3 and heat-shock proteins essential for HCV replication. ${ }^{22}$ In addition to these molecular mechanisms, we investigated the contribution of oxidative/nitrosative stress and lipid metabolism modulation to the inhibition of HCV replication by quercetin.

As previously indicated, a strong relationship between oxidative/nitrosative stress and HCV infection has been reported. ${ }^{4-7}$ In the present research, quercetin was able to significantly inhibit HCV-induced ROS and RNS formation in HCV-replicating cells through its antioxidant activity. It has been also described that HCV replication induces lipid peroxidation that in turn reduces the amount of $\mathrm{HCV}$ RNA. $^{30}$ In our HCV replicon system, quercetin was able to decrease HCV-induced lipoperoxidation, but only slightly, thus maintaining its ability to inhibit HCV replication. IFN $\alpha$ treatments also reduced HCV-induced ROS/RNS generation and lipid peroxidation as previously indicated in chronic hepatitis C patients. ${ }^{39,40}$ The effects of IFN $\alpha$ on redox status seem to be directly mediated by reducing HCV replication. ${ }^{41}$

Liver steatosis is one of the most important histopathological features in patients with chronic hepatitis C. Both viral and host factors contribute to the development of steatosis, and putative defects caused by ROS/RNS may be involved through abnormalities in lipid metabolism. ${ }^{7,9,11}$ In addition, several reports suggest that lipid biosynthesis affects HCV replication..$^{14,42,43}$ Furthermore, some dietary flavonoids appear to regulate lipogenic genes and fatty acid synthesis in in vivo and in vitro models. ${ }^{44-46}$ Thus, it has been previously described that quercetin decreased de novo fatty acid and triacylglycerol synthesis in rat hepatocytes. ${ }^{31}$ In our study, quercetin was able to dose dependently decrease induced lipid accumulation in replicon-containing cells, mainly by reducing TG content, at least in part by inhibiting core expression, which interferes with TG turnover. ${ }^{47}$ However, there is increasing evidence on the central role of non-TG lipotoxicity in the pathogenesis of steatosis. In fact, the accumulation of TG in the form of lipid droplets within the liver may be protective whereas toxic metabolites derived from FFAs could lead to steatosis. ${ }^{48}$ In this regard, in HCV-replicating cells quercetin reduced FFA concentration, responsible for the lipotoxic effects associated with steatosis.
IFN $\alpha 50$ was also able to decrease total intracytoplasmatic lipid and TG accumulation, as described in Huh7 cells expressing HCV genes. ${ }^{49}$ Similarly, FFA concentration was reduced by IFN $\alpha$, as previously observed in serum of HCVinfected patients. ${ }^{50}$

It has been previously described that $\operatorname{LXR} \alpha$ induces the expression of lipogenic genes involved in fatty acid synthesis, including its target FAS. ${ }^{32}$ Recently, we reported that HCV replication induces LXR $\alpha$-mediated intracellular lipid accumulation which in turn contributes to the efficient replication of HCV. ${ }^{15}$ In the current study, quercetin was able to significantly decrease $\mathrm{HCV}$-mediated LXR $\alpha$ induction and subsequent FAS overexpression at all experimental concentrations. While it has been previously described that several flavonoids reduced $\operatorname{LXR} \alpha$ in non-hepatic cells, ${ }^{51-53}$ our results indicate for the first time a role for quercetin in LXR $\alpha$ gene expression and lipid accumulation modulation in LXR $\alpha$-overexpressing and replicon-containing Huh7 cells. Interestingly, IFN $\alpha$ also reversed LXR $\alpha$-mediated FAS induction observed in HCV-replicating cells. A similar decrease in FAS expression by IFN $\alpha$ has been previously indicated in in vitro models of HCV. ${ }^{49}$ However, in the present study IFN $\alpha$ was not able to repress the overexpression of the nuclear receptor $\operatorname{LXR} \alpha$ in Huh7 cells infected with the adenoviral vector, suggesting that the effect of IFN $\alpha$ on lipogenesis modulation can be indirectly mediated by its anti-HCV activity.

We have recently shown that LY294002-mediated PI3K pathway inhibition attenuates $\operatorname{LXR} \alpha$ upregulation induced by HCV expression, ${ }^{15}$ which represents a specific mechanism through which HCV infection alters the cellular lipid profile and causes steatosis. In the current research, HCV-induced PI3K/AKT activation was dose dependently inhibited by quercetin, suggesting a role for PI3K signaling pathway activity in quercetin-mediated $\operatorname{LXR} \alpha$ modulation. In this respect, LY294002, which is in fact a derivative of quercetin, ${ }^{54}$ exerted a similar inhibitory effect on $\mathrm{LXR} \alpha$ overexpression and lipid accumulation-mediated HCV replication capacity, showing an additive effect when combined with quercetin. Therefore, reduction in PI3K/AKT-LXR $\alpha$-mediated hepatic fatty acid synthesis may represent an important mechanism underlying the HCV replication modulatory effect of quercetin. Similarly, PI3K/AKT-sterol regulatory element binding protein (SREBP)-1c suppression by curcumin also inhibits HCV replication in an in vitro model. ${ }^{34}$ In our in vitro model of LXR $\alpha$ overexpression, quercetin could exert its inhibitory effect on $\operatorname{LXR} \alpha$ expression and lipid accumulation not only through modulation of PI3K pathway but also the expression of a large number of miRNAs involved in cell signaling and metabolism, which could in turn cause downregulation of CMV-expressed LXR $\alpha .{ }^{55}$ However, further investigations are required to study this issue.

It has been described that quercetin bound to PI3K results in the inhibition of PI3K activity. ${ }^{56}$ Otherwise, it has been suggested that HCV gene expression induces activation of 
PI3K/AKT via oxidative stress and calcium signaling. ${ }^{26}$ As previously indicated, HCV proteins induce oxidative stressmediated $\mathrm{Ca}^{2+}$ homeostasis alterations, ${ }^{6}$ which might underlie the effects of HCV expression on the PI3K/AKT pathway. In fact, it has been shown that quercetin suppressed the endoplasmic reticulum stress caused by $\mathrm{Ca}^{2+}$ dynamics dysregulation by the inhibition of PI3K. ${ }^{57}$ Thereby, quercetin can also modulate the PI3K/AKT pathway by reducing HCVrelated ROS and RNS generation.

The PI3K pathways have emerged as a critical additional component of IFN-induced signaling. ${ }^{58}$ Thus, the IFNinduced PI3K/AKT pathway is the essential signal for cell survival and thought to be one mechanism for chronic HCV infection. ${ }^{58,59}$ In this study, IFN $\alpha$ treatment is able to interfere with the PI3K/AKT pathway as shown by a dosedependent induction of Ser 473 phosphorylation of AKT. However, the treatment with PI3K inhibitors did not influence IFN-induced anti-HCV replication, indicating that its anti-HCV activity is not PI3K/AKT dependent, as previously reported. ${ }^{60}$

In conclusion, our results suggest that quercetin might exert its inhibitory effect on HCV replication at least in part through oxidative/nitrosative stress inhibition and subsequent lipid metabolism modulation, by reducing PI3K/ AKT-mediated LXR $\alpha$ overexpression and lipid accumulation associated with steatosis development and hepatitis $\mathrm{C}$ progression. Thus, the importance of therapeutic approaches focusing on oxidative/nitrosative stress and associated steatosis in $\mathrm{HCV}$ patients is expected to increase in the near future.

Supplementary Information accompanies the paper on the Laboratory Investigation website (http://www.laboratoryinvestigation.org)

\section{ACKNOWLEDGMENTS}

This work was supported by grants to Javier González-Gallego from Ministerio de Educación y Ciencia (BFU2010-15784), Francisco Jorquera from Junta de Castilla y León (GRS 482/A/10), Pedro L Majano from Ministerio de Ciencia e Innovación, Instituto de Salud Carlos III, FEDER (PI10/ 00101), and Ramiro Jover from Fondo de Investigación Sanitaria (FIS), Instituto de Salud Carlos III (PI10/00194). María V García-Mediavilla and Marta Benet were supported by CIBERehd contracts. CIBERehd is funded by the Instituto de Salud Carlos III, Spain. Sandra Pisonero-Vaquero was supported by the program 'Formación del Profesorado Universitario' (FPU, AP2009-4484) from the Ministry of Education (Spain).

\section{DISCLOSURE/CONFLICT OF INTEREST}

The authors declare no conflict of interest.

1. Reed KE, Rice CM. Overview of hepatitis C virus genome structure, polyprotein processing, and protein properties. Curr Top Microbiol Immunol 2000;242:55-84.

2. Huang $Y$, Staschke K, De Francesco R, et al. Phosphorylation of hepatitis $C$ virus NS5A nonstructural protein: a new paradigm for phosphorylation-dependent viral RNA replication? Virology 2007;20:1-9.

3. Sheikh M, Choi J, Qadri I, et al. Hepatitis C virus infection: molecular pathways to metabolic syndrome. Hepatology 2008;47:2127-2133.
4. García-Mediavilla MV, Sánchez-Campos $S$, González-Pérez $P$, et al. Differential contribution of hepatitis C virus NS5A and core proteins to the induction of oxidative and nitrosative stress in human hepatocytederived cells. J Hepatol 2005;43:606-613.

5. Choi J, Ou JH. Mechanisms of liver injury. III. Oxidative stress in the pathogenesis of hepatitis C virus. Am J Gastroenterol Liver Physiol 2006;290:G847-G851.

6. Dionisio N, García-Mediavilla MV, Sánchez-Campos S, et al. Hepatitis C virus NS5A and core proteins induce oxidative stress-mediated calcium signalling alterations in hepatocytes. J Hepatol 2009;50: 872-882.

7. González-Gallego J, García-Mediavilla MV, Sánchez-Campos S Hepatitis C virus, oxidative stress and steatosis: current status and perspectives. Curr Mol Med 2011:11:373-390.

8. Lonardo A, Loria P, Adinolfi LE, et al. Hepatitis C and steatosis: a reappraisal. J Viral Hepat 2006;13:73-80.

9. Negro F, Sanyal AJ. Hepatitis C virus, steatosis and lipid abnormalities: clinical and pathogenic data. Liver Int 2009;29:26-37.

10. Negro F. Hepatitis C virus-induced steatosis: an overview. Dig Dis 2010:28:294-299.

11. Vidali M, Tripodi MF, Ivaldi A, et al. Interplay between oxidative stress and hepatic steatosis in the progression of chronic hepatitis C. J Hepatol 2008;48:399-406.

12. Yamaguchi A, Tazuma S, Nishioka $T$, et al. Hepatitis C virus core protein modulates fatty acid metabolism and thereby causes lipid accumulation in the liver. Dig Dis Sci 2005;50:1361-1371.

13. $\mathrm{Kim} \mathrm{K}, \mathrm{Kim} \mathrm{KH}, \mathrm{Ha} \mathrm{E}$, et al. Hepatitis $\mathrm{C}$ virus NS5A protein increases hepatic lipid accumulation via induction of activation and expression of PPARgamma. FEBS Lett 2009;583:2720-2726.

14. Kapadia SB, Chisari FV. Hepatitis C virus RNA replication is regulated by host geranylgeranylation and fatty acids. Proc Natl Acad Sci USA 2005;102:2516-2566.

15. García-Mediavilla MV, Pisonero-Vaquero S, Lima-Cabello E, et al. Liver X receptor $\alpha$-mediated regulation of lipogenesis by core and NS5A proteins contributes to $\mathrm{HCV}$-induced liver steatosis and HCV replication. Lab Invest 2012;9:1191-1202.

16. Jagtap S, Meganathan K, Wagh V, et al. Chemoprotective mechanism of the natural compounds, epigallocatechin-3-O-gallate, quercetin and curcumin against cancer and cardiovascular diseases. Curr Med Chem 2009:16:1451-1462.

17. Tuñón MJ, García-Mediavilla MV, Sánchez-Campos S, et al. Potential of flavonoids as anti-inflammatory agents: modulation of inflammatory gene expression and signal transduction pathways. Curr Drug Metab 2009;10:256-271.

18. González-Gallego J, García-Mediavilla MV, Sánchez-Campos S, et al. Fruit polyphenols, immunity and inflammation. Br J Nutr 2012;104: S15-S27.

19. Polyak SJ, Morishima C, Hawke R. Antiviral effects of silymarin against hepatitis C: the jury is still out. Hepatology 2008;48:345-346.

20. Rutter K, Scherzer TM, Beinhardt S, et al. Intravenous silibinin as "rescue treatment" for on-treatment non-responders to pegylated interferon/ribavirin combination therapy. Antivir Ther 2011;16: 1327-1333.

21. Gonzalez O, Fontanes V, Raychaudhuri S, et al. The heat shock protein inhibitor quercetin attenuates hepatitis C virus production. Hepatology 2009;50:1756-1764.

22. Bachmetov L, Gal-Tanamy M, Shapira A, et al. Suppression of hepatitis $C$ virus by the flavonoid quercetin is mediated by inhibition of NS3 protease activity. J Viral Hepat 2012;19:e81-e88.

23. Wagoner J, Negash A, Kane OJ, et al. Multiple effects of silymarin on the hepatitis C virus lifecycle. Hepatology 2010;51:1912-1921.

24. Crespo I, García-Mediavilla MV, Almar M, et al. Differential effects of dietary flavonoids on reactive oxygen and nitrogen species generation and antioxidant enzymes in Chang Liver cells. Food Chem Toxicol 2008;46:1555-1569.

25. Benedicto I, Molina-Jiménez F, Barreiro O, et al. Hepatitis C virus envelope components alter localization of hepatocyte tight junction associated proteins and promote occludin retention in the endoplasmic reticulum. Hepatology 2008;48:1044-1053.

26. Waris G, Felmlee DJ, Negro F, et al. Hepatitis C virus induces proteolytic cleavage of sterol regulatory element binding proteins and stimulates their phosphorylation via oxidative stress. J Virol 2007;81:8122-8130. 
27. Crespo I, García-Mediavilla MV, Gutiérrez B, et al. A comparison of the effects of quercetin and kaempferol on cytokine-induced proinflammatory status of cultured human endothelial cells. Br J Nutr 2008; 100:968-976.

28. Miquilena-Colina ME, Lima-Cabello E, Sánchez-Campos S, et al. Hepatic fatty acid translocase CD36 upregulation is associated with insulin resistance, hyperinsulinaemia and increased steatosis in non-alcoholic steatohepatitis and chronic hepatitis C. Gut 2011;60:1394-1402.

29. Gómez-Foix AM, Coats WS, Baqué $S$, et al. Adenovirus mediated transfer of the muscle glycogen phosphorylase gene into hepatocytes confers altered regulation of glycogen metabolism. J Biol Chem 1992;267:25129-25134.

30. Huang $\mathrm{H}$, Chen $\mathrm{Y}, \mathrm{Ye}$ J. Inhibition of hepatitis $\mathrm{C}$ virus replication by peroxidation of arachidonate and restoration by vitamin E. Proc Nat Acad Sci USA 2007;107:18666-18670.

31. Gnoni GV, Paglialonga G, Siculella L. Quercetin inhibits fatty acid and triacylglycerol synthesis in rat-liver cells. Eur J Clin Invest 2009;39: 761-768.

32. Yoshikawa $T$, Shimano $H$, Amemiya-Kudo $M$, et al. Identification of liver $\mathrm{X}$ receptor-retinoid $\mathrm{X}$ receptor as an activator of the sterol regulatory element-binding protein 1c gene promoter. Mol Cell Biol 2001;21: 2991-3000.

33. Tsubota A, Fujise K, Namiki Y, et al. Peginterferon and ribavirin treatment for hepatitis C virus infection. World J Gastroenterol 2011;17:419-432.

34. Kim K, Kim KH, Kim HY, et al. Curcumin inhibits hepatitis C virus replication via suppressing the Akt-SREBP-1 pathway. FEBS Lett 2010;584:707-712.

35. Feld JJ, Hoofnagle $\mathrm{JH}$. Mechanism of action of interferon and ribavirin in treatment of hepatitis C. Nature 2005;436:967-972.

36. Schindler C, Levy DE, Decker T. JAK-STAT signaling: from interferons to cytokines. J Biol Chem 2007;282:20059-20063.

37. Tai ZF, Zhang GL, Wang F. Identification of small molecule activators of the janus kinase/signal transducer and activator of transcription pathway using a cell-based screen. Biol Pharm Bull 2012;35:65-71.

38. Khachatoorian R, Arumugaswami V, Ruchala P, et al. A cell-permeable hairpin peptide inhibits hepatitis $C$ viral non-structural protein 5A-mediated translation and virus production. Hepatology 2012;55: 1662-1672.

39. Higueras V, Raya A, Rodrigo JM, et al. Interferon decreases serum lipid peroxidation products of hepatitis C patients. Free Radic Biol Med 1994;16:131-133.

40. Romero MJ, Bosch-Morell F, Romero B, et al. Serum malondialdehyde: posible use for the clinical management of chronic hepatitis $\mathrm{C}$ patients. Free Radic Biol Med 1998;25:993-997.

41. Ando $M$, Korenaga $M$, Hino $K$, et al. Mitochondrial electron transport inhibition in full genomic hepatitis $C$ virus replicon cells is restored by reducing viral replication. Liver Int 2008;28:1158-1166.

42. Yang W, Hood BL, Chadwick SL, et al. Fatty acid synthase is upregulated during hepatitis $C$ virus infection and regulates hepatitis $C$ virus entry and production. Hepatology 2008;48:1396-1403.

43. Syed $\mathrm{GH}$, Siddiqui A. Effects of hypolipidemic agent nordihydroguaiaretic acid on lipid droplets and hepatitis C virus. Hepatology 2011;54:1936-1946.
44. Brusselmans $\mathrm{K}$, Vrolix R, Verhoeven $\mathrm{G}$, et al. Induction of cancer cell apoptosis by flavonoids is associated with their ability to inhibit fatty acid synthase activity. J Biol Chem 2005;280:5636-5645.

45. Odbayar TO, Badamhand D, Kimura T, et al. Comparative studies of some phenolic compounds (quercetin, rutin, and ferulic acid) affecting hepatic fatty acid synthesis in mice. J Agric Food Chem 2006;54: 8261-8265.

46. Jung $\mathrm{CH}$, Cho I, Ahn J, et al. Quercetin reduces high-fat diet-induced fat accumulation in the liver by regulating liver metabolism genes. Phytother Res 2013;27:139-143.

47. Harris C, Herker E, Farese RV, et al. Hepatitis C virus core protein decreases lipid droplet turnover: a mechanism for core-induced steatosis. J Biol Chem 2011;49:42615-42625.

48. Neuschwander-Tetri BA. Nontriglyceride hepatic lipotoxicity: the new paradigm for the pathogenesis of NASH. Curr Gastroenterol Rep 2010;12:49-56.

49. Toyoda M, Kitaoka A, Machida K, et al. Association between lipid accumulation and the cannabinoid system in Huh7 cells expressing HCV genes. Int J Mol Med 2011;27:619-624.

50. Konrad T, Zeuzem S, Vicini $P$, et al. Evaluation of factors controlling glucose tolerance in patients with HCV infection before and after 4 months therapy with interferon-alpha. Eur J Clin Invest 2000;30: 111-121.

51. Kaul D, Sikand K, Shukla AR. Effect of green tea polyphenols on the genes with atherosclerotic potential. Phytother Res 2004;18:177-179.

52. Moon HS, Chung CS, Lee HG, et al. Inhibitory effect of (-) epigallocatechin-3-gallate on lipid accumulation of 3T3-L1 cells. Obesity 2007;15:2571-2582

53. Lee J, Jung $\mathrm{E}$, Lee J, et al. Isorhamnetin represses adipogenesis in 3R3L1 cells. Obesity 2009;17:226-232.

54. Imai Y, Yoshimori M, Fukuda K, et al. The PI3K/Akt inhibitor LY294002 reverses $B C R P$-mediated drug resistance without affecting $B C R P$ translocation. Oncol Rep 2012;27:1703-1709.

55. Milenkovic D, Deval C, Gouranton E, et al. Modulation of miRNA expression by dietary polyphenols in apoE deficient mice: a new mechanism of the action of polyphenols. PLoS ONE 2012;7 e29837.

56. Hwang MK, Song NR, Kang NJ, et al. Activation of phosphatidylinositol 3-kinase is required for tumor necrosis factor-alpha-induced upregulation of matrix metalloproteinase-9: its direct inhibition by quercetin. Int J Biochem Cell Biol 2009;41:1592-1600.

57. Natsume $\mathrm{Y}$, Ito $\mathrm{S}$, Satsu $\mathrm{H}$, et al. Protective effect of quercetin on ER stress caused by calcium dynamics dysregulation in intestinal epithelial cells. Toxicology 2009;258:164-175.

58. Kaur S, Uddin S, Platanias LC. The PI3' kinase pathway in interferon signaling. J Interferon Cytokine Res 2005;25:780-787.

59. Mannová P, Beretta L. Activation of the N-Ras-PI3K-Akt-mTOR pathway by hepatitis $C$ virus: control of cell survival and viral replication. J Virol 2005;79:8742-8749.

60. Matsumoto A, Ichikawa T, Nakao K, et al. Interferon-alpha-induced mTOR activation is an anti-hepatitis $C$ virus signal via the phosphatidylinositol 3-kinase-Akt-independent pathway. J Gastroenterol 2009:44:856-863. 